\title{
Classroom Discourse and Student Learning
}

\author{
Yani Zhang \\ School of Foreign Languages, Qingdao University of Science and Technology \\ Qingdao 266061, China \\ E-mail: pennyzhyn@hotmail.com
}

\begin{abstract}
This paper discusses the interrelation between classroom discourse and student learning. The purpose is to reveal that student learning is closely linked to the quality of classroom talk. The author concludes by giving suggestions on how to promote the quality of classroom talk and further facilitate student learning.
\end{abstract}

Keywords: Authentic questions, Classroom discourse, Non-traditional lessons, Student learning

\section{Introduction}

In classroom learning and teaching, a large proportion of time is spent in talking and listening. Being one basic medium of classroom interaction, talking should play a crucial part in the process of learner development. But how important is it? Does the quality of talk accord with the quality of classroom learning? On the basis of these questions, Daniels (2001 cited in Alexander, 2004:8) argues that classroom talk not only mediates teaching and learning but the wider culture. Alexander (2004:9) also indicates that talk is necessary for 'the building of the brain itself as a physical organism and thereby expanding its power'. Moreover, the quality of classroom discourse is of great importance because it sets a suitable climate for learning and transmitting teachers' expectations for their pupils' thinking (Nystrand, 1997:28).

However, perhaps because talking is impermanent and evanescent compared with written words, many people tend to be less reflective about spoken discourse than written in classrooms; besides, this lower status of talking is constantly strengthened by teachers as well as parents (Alexander, 2004). For instance, Alexander (2004:6) points out that it is always written work that is regarded as 'real school work and as the most reliable medium for measuring pupil's learning'. Barnes (1992:124) also implies that learning is not simply adding bits of information to the previous knowledge. Rather, most important learning is a matter of 'working on understanding', which can be achieved through talk (ibid).

In an effort to reveal the importance of classroom talk in student learning and their interrelation, this paper aims to discuss whether student learning is closely linked to the quality of classroom talk. First, theories from Vygotsky and Halliday concerning the correlation between language and learning are elaborated. Secondly, varieties of classroom discourse are considered. Afterwards, nature of the discourse varieties is uncovered. Finally, the role of talk in classroom learning is discussed.

\section{Language and Learning}

During the activity of acquiring new knowledge, many factors may affect the quality of learning, such as: learning styles, learner strategies, different learner variables (motivation, age, and gender) as well as classroom discourse. Being the medium of classroom learning/teaching, language plays a significant role in affecting the kinds of opportunities for knowing and coming to know as well as in encouraging collaborative group work (Wells, 1999:114). Wells (ibid) insists that when talking in groups or whole class, pupils can learn a great deal from each other and present the significance of what they have done and come to understand in front of the teacher. Likewise, Nystrand (1997:29) points out that certain kinds of classroom talk creates more opportunity and flexibility for students to contextualize and assimilate new information.

Many researches have been done to investigate the relationship between language and learning, among which Vygotsky's ZPD and Halliday's language based-theory of learning are the most influential and representative. Being one of the most prominent psychologists, Vygotsky (1978:86) explains the interaction between learning and development, among which the concept of the zone of proximal development (ZPD) is the central idea. He defines ZPD as 'the distance between the actual developmental level as determined by independent problem solving and the level of potential development as determined through problem solving under adult guidance or in collaboration with more capable peers' (Vygotsky, 1978:86). In other words, a zone exists in the process of children development, which concerns the difference between a child's performances with or without other's assistance (Wells, 1999:313). According to Wells (1999:319), learning and teaching in the ZPD obviously depends on social interaction, and this certainly 
involves 'face-to-face interaction mediated by speech' in classrooms. Besides, he also believes in Vygotsky's claim, namely, speech plays a critical role in children's learning in the ZPD and in the processes of assistance and instruction (ibid).

Compatible and complementary to Vygotsky's theory, Halliday also argues that discourse plays a central role at all levels of education. As Wells (1999:xiii-36) points out, Vygotsky stresses more in the ways language influences mental functions and how language functions inner speech, while Halliday pays more attention to 'language in its social uses', 'the relationships between spoken and written texts', and 'the situations in which languages are created and interpreted'. His functional approach contributes to establish some general principles about the use of language. First, the ideational function of language serves for the expression of context; second, the interpersonal function works when language is used as a means of intrusion into the speech event; third, textual function enables language to make links with the internal organization of sentences and its meaning (Halliday, 1976:105-7).

\section{Varieties of classroom discourse}

Having considered the relationship between language and learning, I will begin this next section by discussing two different types of classroom discourse, traditional and non-traditional lessons. Cazden (2001) makes an explicit contrast between the two categories. On one hand, traditional lessons refer to the using of a three-part sequence: teacher initiation, student response, and teacher evaluation or follow-up (IRE or IRF). Lemke describes this format as 'triadic dialogue' (Wells, 1999:167).

Non-traditional lessons, on the other hand, means the sequence of talk in classrooms does not fit an IRE structure on account of a changed educational goal (Cazden, 2001:31). These two prominent alternatives of classroom discourse have earlier been differentiated by Bakhtin (1981 cited in Skidmore, 2000:284) as 'authoritative discourse' and 'internally persuasive discourse'. To be more precise, the former means 'someone who knows and possesses the truth instructs someone who is ignorant of it and in error'; while the later refers to more students' responses, student self-selection and students' topic expansion (Skidmore, 2000). Thus, it is obvious that in traditional lessons teachers generally dominate the class talk; students have fewer opportunities to ask their own questions or generate subtopics (Gutierrez, 1994).

However, according to Wells (1999:167), the IRE structure in teaching takes up about 70 percent of all the classroom discourses in many secondary schools as well as some primary ones. In a research conducted by Nystrand (1997), it was also found that the dominated pattern of classroom interaction was monologically-organised instruction, i.e. traditional IRE sequences rather than dialogically-organized form which can promote 'retention and in-depth processing associated with the cognitive manipulation of information'. This view is also supported by Wood (1992) and Lemke (1990), who advocate teachers to use a less controlling type of discourse to encourage student participation to the largest extent.

\section{Nature of the Varieties}

Subsequently, it brings us to consider what factors lead to the two different classroom discourses. According to Skidmore (2000:292), it is the inherent nature of the task for the students to complete that results in the differences. That is, what types of questions given by the teachers engender the distinctions. Questions are applied to check learners' attention, evaluate rote learning, and even to stimulate their thinking and discussion. Wood (1992:205) claims that questions may 'motive, sustain and direct the thought processes of the pupil' and promote reflection as well as self-examination. Apparently, questions have significant effects on classroom activities.

But will all questions equally contribute to student learning? Skidmore (2003) analyzes three categories of questioning: questions with one right answer; with a finite set of right answers and with an indeterminate though bounded set of possible answers. The first type, namely, closed or two-choice questions are criticized for not only failing to promote pupils' deep thinking but also inhibiting their intellectual activity (Wood, 1992:205). Wood (ibid) also argues that the use of closed and Wh-type questions can result in pupils' short responses, less participation and misunderstanding. The second type is more open-ended and has more 'cognitively challenging quality' than the first; while the third type, questions with an indeterminate number of possible answers are authentic which the teacher does not know what the pupils will answer (Skidmore, 2003:50). As Nystrand and Gamoran (1997:73) state, only authentic discourse can engage students, and authentic questions must stimulate pupils to think and reflect on the consequences of their ideas, not just recall their past experiences.

Therefore, teachers should identify when frequent questions are needed and what types of questions are appropriate. From my point of view, authentic questions are in no doubt helpful in promoting learners' thinking and accelerating the learning process. Nonetheless, because closed questions can rapidly examine students' understanding and knowledge in classroom interaction, I believe that closed questions are correlated with the efficiency of classroom teaching. If the efficiency is lost, the teacher can not possibly complete the teaching task, then how can students have chances to learn more? So in my opinion, teacher should avoid using closed questions frequently, but apply more open-ended ones at proper occasion. In order to strike a balance, teachers should take into account many factors, such as: the teaching 
situation, classroom size, pressure from the centrally prescribed curriculum, culture diversities, etc.

For instance, if there are a large number of students in one classroom, say sixty, then it will be impossible to ask many open-ended questions in a fifty-minute' period. In that case, what the teacher could do is trying to afford as many opportunities as possible to enhance students' participation. Another factor is learners' different culture background. From the viewpoint of a teacher and a learner being educated in China, I think that some pupils would prefer closed questions. They seldom express their thoughts in front of other peers or the teacher. Moreover, they are usually not encouraged to have diverse opinions about what they have learned. It seems that what the teacher is saying is the truth and nobody should doubt the authoritative perspective from the teacher, the teachers' books or the syllabus. So open-ended questions are rarely proposed in favor of saving time. This culture factor brings about convergent understanding and progress in Chinese learners, but not divergence. Also, there is this pressure from the centrally prescribed curriculum. Since all teachers have to complete the tasks in the curriculum and handle all kinds of exams, the application of authentic questions becomes harder and less popular.

\section{The role of classroom talk in student learning}

Being one basic means of teaching, talk is 'arguably the true foundation of learning' (Alexander, 2004:5). It is through talk that children actively engage and teachers constructively intervene (ibid). In Alexander's (2004) classroom research conducted around the world, it is found that most teachers basically use three kinds of classroom talk: 'rote' means mechanically practicing facts, ideas and routines; 'recitation' refers to the accumulation of knowledge and understanding through questions to test the pupils' previous knowledge or to apply them clues in the question to work it out; 'instruction/exposition' concerns 'telling the pupil what to do, imparting information and explaining facts, principles or procedures'.

Still, some teachers apply two additional kinds of classroom talk which have greater cognitive potential: discussion and scaffolded dialogue. The former, existing between teacher-class, teacher-group or pupil-pupil, means the exchange of ideas in sharing information and solving problems (Alexander, 2000:527). While the latter refers to 'achieving common understanding through structured and cumulative questioning and discussion which guide and prompt, reduce choices, minimize risk and error, and expedite 'handover' of concepts and principles' (ibid). Perhaps because scaffolded dialogue is more complicated and requires more teacher skills, it remains less common in classroom teaching. Alexander (ibid) summarized the role of different kinds of talk in scaffolding as follows: rote can not scaffold, basic recitation offers few opportunities, but well-designed instruction or discussion can help to scaffold effectively.

Therefore, we can summarize that various kinds of talk are unlikely to contribute equally to student learning. Barnes (1992:126) distinguishes two functions of talk between presentational and exploratory talk. Presentational talk, on one hand, focuses more on the needs of the teacher than on the student's own ideas. It usually occurs when teacher is trying to seek answers from students to test their understanding of a topic already taught. On the other hand, exploratory talk enables learners to 'try out ideas, to hear how they sound, to see what others make of them, to arrange information and ideas into different patterns' (ibid). Because much of the talk elicited from pupils is essentially presentational, Barnes (1992:126) proposes that teachers consider when and where to employ presentational or exploratory talk and ensure a balance of them.

From my viewpoint, Barnes's classification about functions of talk is explicit. The presentational talk shows the function of speaking in traditional IRE sequence. While in dialogically-organised instruction, talk operates its exploratory function. Similar to questions, the quality of classroom talk consequently depends on various factors, such as: closed or authentic questions, traditional IRE sequence or internally persuasive discourse, classroom organization, the communicative skills of children and teachers, classroom size, centrally prescribed curriculum, culture, etc.

\section{Conclusion}

From the above discussion, we can conclude that the quality of student learning is closely associated with the quality of classroom discourse. Thus, as teachers, we should attach more importance to spoken discourse during classroom interaction. We should manage to act more often as consultants but not just mere transmitters of information; we should recognize various group-based discussions as real work; and we should encourage students to generate their own questions and to explore alternative answers. Moreover, authentic questions should be structured to encourage thoughtful answers, and further student questions built on previous responses are promoted. In addition, oral tasks should be given greater prominence than it is in the traditional ratio of spoken and written tasks. In order to achieve this, teachers ought to improve self-teaching skills. If we can improve the quality of classroom discourse, we can certainly raise the quality of student learning.

\section{References}

Alexander, R. J. (2000). Culture and Pedagogy: International Comparisons in Primary Education, Oxford: Blackwell

Alexander, R. J. (2004). Towards Dialogic Teaching: Rethinking Classroom talk, Cambridge: Dialogos 
Barnes, D. (1992). The Role of Talk in Learning' in Norman, K. (1992). Thinking Voices: The Work of the National Oracy Project, London: Hodder \& Stoughton pp.123-128

Cazden, C.B. (2001). Classroom Discourse: The Language of Teaching and Learning, Portsmouth, (2 ${ }^{\text {nd }}$ ed.), NH: Heinemann

Gutierrez, K. D. (1994). How talk, context, and script shape contexts for learning: a cross-case comparison of journal sharing. Linguistics and Education, 5, pp. 335-365

Halliday, M.A.K. (1976). Explorations in the Functions of Language, London: Oxford: Blackwell

Nystrand, M. (1997). 'Dialogic Instruction: When Recitation Becomes Conversation' in Nystrand, et al (1997). Opening Dialogue: Understanding the Dynamics of Language and Learning in the English Classroom, New York: Teachers College Press pp.1-29

Nystrand, M. \& Gamoran, A. (1997). 'The Big Picture: Language and Learning in Hundreds of English Lessons' in Nystrand et al (1997). Opening Dialogue: Understanding the Dynamics of Language and Learning in the English Classroom, New York: Teachers College Press pp. 30-74

Skidmore, D. (2000)..From pedagogical dialogue to dialogical pedagogy. Language and Education, 14(4), pp. $283-296$

Skidmore, D., Perez-Parent, M., \& Arnfielf, S. (2003). Teacher-pupil dialogue in the guided reading session. Reading: Literacy and Language, 37(2), pp47-53

Vygotsky, L.S. (1978). Mind in Society: The Development of Higher Psychological Processes, Cambridge, MA: Harvard University Press

Wells, G. (1999). Dialogic Inquiry: Towards a Sociocultural Practice and Theory of Education, Cambridge: Cambridge University Press.

Wood, D. (1992). 'Teaching Talk: How Modes of Teacher Talk Affect Pupil Participation' in Norman, K. (1992) Thinking Voices: the Work of the National Oracy Project, London: Hodder \& Stoughton pp. 203-214 